\title{
Bacterial contaminations of raw cow's milk consumed at Jigjiga City of Somali Regional State, Eastern Ethiopia
}

\author{
Melese Abate Reta ${ }^{1 *}$, Tesfaye Wolde Bereda ${ }^{2}$ and Ayalew Nigusie Alemu ${ }^{3}$
}

\begin{abstract}
Background: Milk is a compensatory part of daily diet especially for the expectant mothers as well as growing children. It is virtually a sterile fluid when secreted into alveoli of udder. However, beyond this stage of production, microbial contamination might generally occur from different sources.

Methods: A cross-sectional study was carried out from March 2013-January 2014 in Jigjiga city to assess bacterial contamination of raw milk meant for human consumption and to determine antimicrobial susceptibility patterns of the isolates. A total of 120 raw milk samples were aseptically collected from different sampling points that were hypothesized to be a source of potential contaminations. Data were analyzed using SPSS version 17 computer software. P-value of $<0.05$ was taken as statistical significance.

Results: Overall, the organisms identified and their prevalence rates were Escherichia coli 70(58\%), Staphylococcus aureus 29(24.2 \%), Shigella Sp. 21 (17.5\%), Proteus sp. 9 (7.5 \%) and Salmonella sp. 4 (3.3\%). The isolation rates of these identified bacteria from each sampling points are statistically significant in E. coli and Proteus $s p .(P<0.05)$. High antibiotic resistance for E. coli isolates were observed to Doxycycline (42.3\%) and Ampicillin (30 \%). Shigella sp. was resistant to Ampicillin (38.1\%). Salmonella sp. isolates were highly resistant to Amoxicillin (50\%). Out of a total of 29 S.aureus isolates, high resistance rate was observed to penicillin G 27(93.1 \%) followed by tetracycline 20(69 \%), and very low level of resistance to vancomycin 2(6.9\%) and rifampicin 1(3.4 \%). Multidrug resistance was also observed in $55.2 \%$ of the total isolates.

Conclusions: Considering the high rate of raw milk contamination with the above isolated bacteria, sanitary practice during collecting, transporting and vending is recommended since the consumption of unpasteurized milk may inflict an important public health risk.
\end{abstract}

Keywords: Bacterial contamination, Critical sampling points, Raw milk, Antibiotic, Jigjiga

\section{Background}

Milk is used throughout the world as a human food at least one form or more. It is virtually a sterile fluid when secreted into alveoli of udder. However, beyond this stage of production, microbial contamination might generally occur from different sources (Mennane et al. 2007). Conditions for contamination of raw milk at different critical points are due to less hygienic practices in pre-milking udder preparation, sub-optimal hygiene of

\footnotetext{
* Correspondence: melese1985@gmail.com

${ }^{1}$ Faculty of Health Science, Department of Nursing, Woldia University, P.O.Box 400, Woldia, Ethiopia

Full list of author information is available at the end of the article
}

milk handlers, and poor sanitation practices associated with milking and storage equipments (Garedew et al. 2012). Milk is largely made up of water, within which a wide range of nutrients including vitamins, proteins, fats and carbohydrates are suspended. These rich nutritional contents, the production and processing procedures in commercial milk production render it susceptible to contamination by a host of pathogenic microbes that could cause diseases in humans. Therefore, milk is known to be an efficient vehicle for transmission of disease causing agents to humans (Garedew et al. 2012). The demand of consumers for safe and high quality milk has placed a significant responsibility on dairy producers, retailers and 
manufacturers to produce and market safe milk and milk products (Adesiyun et al. 1995; Mennane et al. 2007). Milk and milk products have important role in feeding the rural and urban population of Ethiopia owing to its high nutritional value. It is produced daily, sold for cash or readily processed. It is a cash crop in the milkshed areas that enables families to buy other foodstuffs and significantly contributing to the household food security (Abebe et al. 2012). Lack of refrigeration facilities at farm and household level in developing countries of tropical regions with high ambient temperature implies that raw milk will easily be spoiled during storage and transportation (Godefay and Molla 2000). Milk and milk products may carry toxic metabolites of different pathogenic organisms growing in it. Ingestion of such products contaminated with these metabolites cause food poisoning for consumers. On the other hand the ingestion of viable pathogenic bacteria along with the food product leads to food borne infection (Aneja et al. 2002). The disease causing bacteria in the milk are Salmonella sp. Mycobacterium bovis, Corynebacterium sp., Clostridium perfringens, Yersinia enterocolitica, Coxiella burnetii, Brucella, Staphylococcus sp., Campylobacter jejuni, Mycobacterium avium, Listeria sp., Escherichia coli, and coliforms (Fadaei 2014; Olatunji et al. 2009). The total coliforms, E. coli and other enteric bacteria are reliable indicators of fecal pollution generally in insanitary conditions of water, food, milk and other dairy products. Recovery of $E$. coli from food is an indicative of possible presence of enteropathogenic and/or toxigenic microorganism which could constitute a public health hazard (Soomro et al. 1996). These microorganisms are usually associated with food borne diseases and outbreaks, as recorded by official health organizations (Bouazza et al. 2012). The presence of these pathogenic bacteria in milk appeared as main public health concerns, especially for those people who still drink unpasteurized raw milk (Claeys et al. 2013). Despite this, the aim of this study was to determine the presence of contaminating microorganisms and their antibiotic resistance patterns in the raw milk produced by individual farmers, collectors and milk vendors in Jigjiga city, eastern Ethiopia.

\section{Methods}

\section{Study area, design and study period}

A cross-sectional study was conducted in Jigjiga city from March 2013-January 2014. Jigjiga is the capital city of Ethiopian Somali Regional State located at $628 \mathrm{~km}$ east of Addis Ababa at $9^{\circ} 20^{\prime}$ north latitude and $42^{\circ} 47^{\prime}$ east longitude. The altitude of the district ranges from 900-1600meters above sea level and receives an annual rainfall of 300-500 $\mathrm{mm}$ with the mean minimum and maximum annual temperatures of $20^{\circ} \mathrm{C}$ and $28^{\circ} \mathrm{C}$ respectively (CSA 2003). The community in this region is pastoral and agro-pastoralist and there is large milk production from cows, camels and goats. The study populations were raw cow's milk from individual farmers' cows, milk collectors, and milk venders in Jigjiga city.

\section{Collection of raw milk samples at critical sampling points and transportation}

Milk samples were collected from points considered to be associated with contamination (critical sampling points). The sampling points were the teat during milking, milking buckets at farm level, transport containers, and selling point up on arrival at the market. Overall, 120 raw milk samples were analyzed: of these, 30 raw milk samples were from teat, 30 from milking buckets, 30 from storage containers, and 30 from selling point up on arrival at the markets. During sampling of raw milk directly from teats, the udder and teats were cleaned and dried before sampling; each teat end was scrubbed gently with cotton swabs moistened with $70 \%$ ethyl alcohol. The first 3-4 streams of milk were discarded, and approximately $10 \mathrm{ml}$ of milk was collected into sterile sampling bottles. The other raw milk samples were collected in the morning following standard safety procedures. Prior to sampling from milking buckets and transport containers, the milk was thoroughly mixed by shaking and $25 \mathrm{ml}$ of milk was transferred into a sterile screw capped bottle. Transportation of samples to the Ethiopian Somali Regional Laboratory was immediately conducted for further processing using ice packs following the standard safety procedures (Robinson 2002).

\section{Bacterial identification and isolation from milk samples}

Detection of E.coli: All the samples positive for E. coli contamination were confirmed using Gram's staining, cultural and biochemical examinations. The samples were inoculated on MacConkey Agar (Difco laboratories, USA) and incubated aerobically at $37^{\circ} \mathrm{C}$ for $24 \mathrm{~h}$. The plates were observed for the growth of $E$. coli. A single, isolated colony was picked and sub-cultured again on MacConkey agar for purification of the isolate. Simultaneously another single colony with similar characters was picked for the preparation of smear and stained with Gram's stain for the examination of staining and morphological characters of the isolate using bright field microscope. The cultural characteristics of the isolates were confirmed by inoculating the pure colonies on Blood Agar (Oxoide, Germany), Nutrient Agar (Oxoid CM0003, Basingstoke, England), Nutrient Broth and Violet Red Bile Agar (Oxoid CM107). Biochemical tests were performed to confirm the E. coli using catalase test, Simmon's Citrate Agar, sugar fermentation on Triple Sugar Iron Agar(Oxoid CM0277, Basingstoke, England), Gelatin liquefaction, Indole Production, Nitrate reduction, Urease production, Voges proskaur, Methyl red and Presumptive test. Detection of Salmonella Sp: The 
isolation and identification involves three steps; $1 \mathrm{ml}$ of milk was pre-enriched with $9 \mathrm{ml}$ of buffered peptone water (Oxoid CM509, Basingstoke, England) and incubated for $24 \mathrm{~h}$ at $37^{\circ} \mathrm{C}$. A portion $(0.1 \mathrm{ml})$ of the preenriched cultured was transferred to $10 \mathrm{ml}$ of selenite cysteine broth (Merck) and incubated at $37^{\circ} \mathrm{C}$ for $24 \mathrm{~h}$ respectively. Finally, from the selective enrichment media the sample was inoculated on to xylose lysine deoxycholate (XLD) agar (Oxoid CM0469, Basingstoke, England) and incubated at $37^{\circ} \mathrm{C}$ for $24 \mathrm{~h}$. Characteristic Salmonella colonies, having a slightly transparent zone of reddish color and a black center were sub-cultured on nutrient agar and confirmed biochemically using triple sugar iron agar (TSI)(Oxoid CM0277, Basingstoke, England), Christensen's urea agar (Oxoid CM53, Basingstoke, England), lysine iron agar (LIA) (Oxoid CM381, Basingstoke, England), Voges Proskauer (VP), methyl red (MR)(Micromaster Thane, India), and Indole tests (Becton Dickinson, USA) (Hendriksen 2003). Detection of S.aureus: Gram staining was performed (Cruikshank et al. 1975) and Gram-positive cocci that occurred in clusters under the microscope were subjected to preliminary biochemical tests (the catalase and oxidase tests). The identities of the isolates were confirmed based on positive results for the DNase test, beta haemolytic patterns on blood agar enriched with $5 \%(\mathrm{v} / \mathrm{v})$ sheep blood and the coagulase slide test for $S$. aureus using the (PROLD Diagnostics, Canada). The slide agglutination test was performed according to the manufacturer's instructions. Briefly, cells from a pure colony were placed on the clean area of the slide using a sterile toothpick and a drop of the PROLD reagent was added. These were mixed using the toothpick and the isolates were identified based on the formation of agglutination. An isolates that formed agglutination were recorded as $S$. aureus and maintained at $4^{\circ} \mathrm{C}$ in $30 \%$ glycerol for further characterization by antibiotic susceptibility testing. Detection of Shigella Sp: Specimens were plated directly on primary media: SalmonellaShigella agar (Merck) and Selenite F broth (Mast Diagnostics DM 210, Mast Diagnostics, UK). For those negative samples on primary sold media, sub-culturing from enrichment broth to primary media was performed to improve recovery of the isolates. All of the inoculated media were incubated at $37^{\circ} \mathrm{C}$ for $18-24 \mathrm{~h}$. The non-black colonies observed on the center were suspected positive test for Shigella sp. and Klingler Iron Agar (KIA) was used for biochemical differentiation of Shigella from other coliform bacteria. Colonies of suspected Shigella was inoculated on Salmonella-shigella Agar plate (Merck), deoxycholate citrate agar (DCA) (Oxoid CM 35; Oxoid Ltd, UK) and incubated at $37^{\circ} \mathrm{C}$ for $24 \mathrm{~h}$. Growth of suspected Shigella sp. change in color butt of media its color(red) to yellow and red slope remained as it is because Shigella $s p$. is lactose fermenter in anaerobic condition. Detection of Proteus
Sp: One $(1 \mathrm{ml})$ of milk sample was enriched in $10 \mathrm{ml}$ of Buffer peptone water aseptically and incubated at $37^{\circ} \mathrm{C}$ for $24 \mathrm{~h}$. Inoculum from the enrichment broth was streaked on Hektoen Enteric Agar (HEA) and MacConkey Agar (Difco laboratories, USA) and incubated at $37^{\circ} \mathrm{C}$ for $24 \mathrm{~h}$. The cultures were identified on the basis of their morphological, and biochemical characteristics.

\section{Antimicrobial susceptibility testing}

The antimicrobial susceptibility patterns of the above detected bacteria were carried out following the KirbyBauer disc diffusion method on Mueller Hinton agar (Oxoid CM0337 Basingstoke, England) as described by the Clinical and Laboratory Standards Institute (CLSI 2008). The criteria used to select the antimicrobial agents tested were based on the availability and frequency of prescription for the management of bacterial infections in animals as well as for human in Ethiopia and on the basis of their different structures and mechanisms of action. Antimicrobial susceptibility test was performed for all $S$. aureus isolates according to the criteria of the Clinical and Laboratory Standards Institute (CLSI 2008). For susceptibility test for S. aureus, one anti-microbial from each subclass of antimicrobials which were commonly used for treatment of bovine mastitis or considered as important antimicrobial agents for human were selected for antibiogram based on the criteria of Clinical and Laboratory Standards Institute (CLSI 2008). Thus, antimicrobials used for treatment of bovine mastitis included in this study were erythro-mycin (E/15 $\mu \mathrm{g})$, cephalothin (KF/30 $\mu \mathrm{g})$, penicillin-G(10unit), sulphoxazole-trimethoprim (SXT/25 $\mu \mathrm{g})$, amoxicillinclavulinic acid (AMC/30 $\mu \mathrm{g}$ ), chloroamphenicol (C/ $30 \mathrm{mg}$ ), (Oxoid), tetracycline (TE/30 $\mu \mathrm{g}$ ) and gentamicin $(\mathrm{CN} / 10 \mu \mathrm{g})$ (Biomerioux). Antimicrobials not used for treatment of bovine mastitis but important for human were oxacillin $(\mathrm{OX} / 1 \mu \mathrm{g})$, vancomycin (VA/30 $\mu \mathrm{g})$, clindamycin (DA/10 $\mu \mathrm{g}$ ) and rifampicin (RD/5 $\mu \mathrm{g}$ ) (Oxoid). Finally, the diameters of the zone of inhibition around the disks were measured to the nearest millimeter using rulers, and the isolates were classified as susceptible, intermediate and resistant (CLSI 2008). E. coli ATCC 25922 was used as a quality control organism for the antimicrobial susceptibility test (Hendriksen, 2002). Moreover, isolates showing resistance to three or more antimicrobial subclass were considered as multidrug resistant.

\section{Statistical analysis}

The collected data for bacterial contamination analysis were entered and analyzed using SPSS version 17 computer software. Accordingly, descriptive statistics such as percentages and frequency distribution was used to describe/present bacterial isolates and antimicrobial susceptibility which was expressed as percent of resistant, 
intermediate and susceptible. $P$-value $<0.05$ was taken as cut-off for statistical significance.

\section{Results}

\section{Isolated bacterial species}

Overall, five bacterial targets were identified in the milk sampled in the study area. The bacteria so identified and their isolation rate were E.coli 70(58 \%), Salmonella sp. 4(3.3\%), Shigella sp. 21(17.5\%), Staphylococcus aureus 29 (24.2 \%) and Proteus Sp. 9(7.5 \%). These are indicative of significant contamination of milk and important human pathogens. The most prevalent organism overall was E. coli, while the least prevalent was Salmonella $s p$. In this study, the contamination degree of milk by the isolated bacteria is utterly worsened at each critical sampling point. High contamination level was observed at market point sampled milk. The difference in isolation rate across market chain (critical sampling points) is statistically significant in E. coli. $(P=0.00)$ and Proteus sp. $(P=0.016)$ (Table 1$)$.

Results of the present study revealed that 49 (40.8\%) of milk sampled had at least two different bacterial organisms, 6 (12\%) from the udder, 10(20.4 \%) milking bucket, $12(24.5 \%)$ from storage container and 21 (42.9\%) from the market point (Fig. 1).

\section{Antimicrobial susceptibility of the bacterial isolates}

The antimicrobial susceptibility tests of the bacterial isolates were grossly very variable. About $76.1 \% \mathrm{E}$. coli isolates were resistant and it had the highest resistance rates to Doxycycline, Ampicillin and Gentamycin (42.3\%, $30 \%$ and $30 \%)$ respectively. A quarter of E. coli isolates $(25.4 \%)$ were multidrug resistant ( $\geq 3$ drugs). Similarly higher antimicrobial resistance $(74.6 \%)$ was recorded against Salmonella $s p$. isolates as well. The highest resistance rate to Salmonella $s p$. was observed in Amoxicillin (50 \%). The highest resistance rate to shigella was observed in Ampicillin (38.1\%). All shigella isolates were highly susceptible to Co-trimoxazole(81\%). About $14 \%$ of Shigella isolates were multidrug resistantfairly better than E.coli isolates. All Proteus sp. isolates were $66.7 \%$ sensitive to Ciprofloxacin and showed (55.6\%) resistance to Ampicillin (Table 2).
The observations made in the present study clearly proved that $S$. aureus showed resistance to all antimicrobials tested except for Rifampicin and Vancomycin. These indicate that the problem is highly distributed and disseminated. Moreover, the overall resistance of $S$. aureus isolates, to Vancomycin, Rifampicin, Clindamycin and Gentamycin showed less than $25 \%$ of resistance. The highest resistance rate was observed in Penicillin (93.1\%), followed by Tetracycline (69\%). On the other hand, about $55.2 \%(16 / 29)$ of S.aureus isolates were found to be multidrug resistant (Table 3).

\section{MAR phenotypes of S. aureus}

Multiple antibiotic resistance (MAR) phenotypes were determined for $S$. aureus (Table 4). The predominant MAR phenotypes for $S$. aureus isolated from this study area were PG-TE -Ox and PG-TE-AC-E-SXZ-Ox in $24.1 \%$ and $17.2 \%$ of the isolates, respectively. Furthermore, MAR phenotypes PG-TE- AC-Ox, PG-TE-AC-E-SXZ-OxCN, PG-TE-AC-E-SXZ-Ox- CN-CH and PG-TE-AC-ESXZ-Ox- CN- VA were obtained in $3.4 \%$ of the isolates. Also PG-TE-AC 6.9 \%, PG-TE-Ox- KF $13.8 \%$ and PG-TEAC-E-Ox $6.9 \%$ were the MAR phenotypes for $S$. aureus isolated from this study area (Table 4).

It is thus evident that MAR $S$. aureus was isolated from all critical sampling points. However, among the isolates from this study area $55.2 \%$ of the isolates develop MAR. Among all MAR phenotypes of S. aureus, $40.3 \%$ of them were resistance to six different antibiotics and $7.2 \%$ were resistance to seven antibiotics. Fifty four percent $(54 \%)$ of them were resistance to 3 or 4 antibiotics.

\section{Discussion}

The outcome of our study revealed that $84.1 \%$ of milk samples were contaminated with at least one bacterium that comprised of E. coli, Salmonella sp., Shigella sp., S. aureus, and Proteus Sp., with isolation rates of 70(58\%), 4(3.3\%), 21(17.5\%), 29(24.2\%), and 9(7.5\%), respectively.

The levels of contamination with each isolated bacteria were higher across critical sampling points (from teats, Milking bucket, transportation container, and at market points). Similar findings reported by Daka et al.(2012) revealed that the level of contamination with S.aureus

Table 1 Occurrence of isolated bacteria across critical sampling points $(n=120)$ of milk collected from Jigjiga city

\begin{tabular}{|c|c|c|c|c|c|c|}
\hline \multirow{2}{*}{$\begin{array}{l}\text { Bacteria } \\
\text { isolated }\end{array}$} & \multirow{2}{*}{$\begin{array}{l}\text { Isolate } \\
\text { No(\%) }\end{array}$} & \multicolumn{4}{|c|}{ No. of positive sample (\%) } & \multirow[t]{2}{*}{$P$-value } \\
\hline & & Udder $(n=30)$ & Collection Bucket $(n=30)$ & Storage Material $(n=30)$ & Market point $(n=30)$ & \\
\hline E. coli & $70(58 \%)$ & $9(30 \%)$ & $16(53.3 \%)$ & $22(73.3 \%)$ & $23(76.7 \%)$ & 0.00 \\
\hline Salmonella sp. & $4(3.3 \%)$ & $1(3.3 \%)$ & $0(0.0 \%)$ & 1(3.3\%) & $2(6.7 \%)$ & 0.140 \\
\hline Shigella sp. & $21(17.5 \%)$ & $4(13.3 \%)$ & $3(10 \%)$ & $4(13.3 \%)$ & 10(33.3\%) & 0.069 \\
\hline S. aureus. & $29(24.2 \%)$ & $6(20 \%)$ & $7(23.3 \%)$ & $6(20 \%)$ & 10(33.3\%) & 0.727 \\
\hline Proteus sp. & $9(7.5 \%)$ & $0(0.0 \%)$ & $2(6.7 \%)$ & $3(10 \%)$ & $4(13.3 \%)$ & 0.016 \\
\hline
\end{tabular}




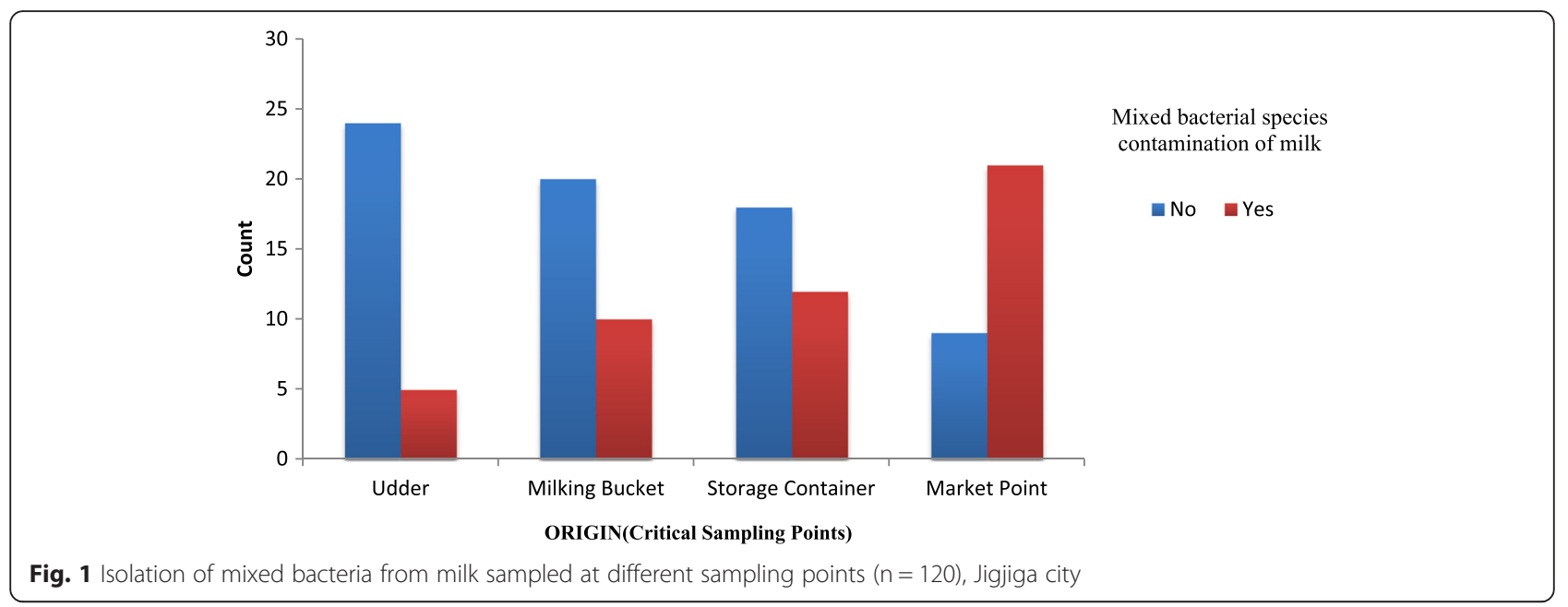

were higher in milk obtained from teat(17.9\%), Milking bucket at farm level(25.7\%), storage containers at milk collection center(26.9 \%) and from transportation container(21.8\%). Conditions for contamination of raw milk at different critical points are due to less hygienic practices in pre-milking udder preparation, sub-optimal hygiene of milk handlers, and poor sanitation practices associated with milking and storage equipments, higher environmental contamination during transportation or contamination during waiting along the roadside (Garedew et al. 2012). Based on observations made during the collection of samples, we therefore report that improper hygiene and poor farm management practices contributed to the presence of these isolated bacteria in the milk. In this study area milk was obtained from animals by washing their hands and/or the utensils and containers used. In certain cases, untreated groundwater was used to wash the containers that were used for milking. This may have contributed to the high level of enteric bacteria and S.aureus isolated. Improving the hygienic conditions of the milking environment and/or utensils may reduce the prevalence of entropatogenic as well as S.aureus in milk and prevent its transmission to humans. Olatunji et al (2009) in Nigeria had reported that higher isolation frequencies of $E$. coli
(24.4 \%), S. aureus (38.2 \%), and Salmonella sp. (2 \%), from apparently normal milk samples from different critical sampling points. It is known that even when drawn under aseptic condition, milk always contains microorganisms which are derived from the milk ducts in the udder, in addition contaminants coming from milking utensils and human handlers (Solomon et al. 2013). Higher isolation frequencies, especially for $E$. coli across market chain was observed in the current study as compared to similar studies performed to assess bacteriological quality of raw milk in Ethiopia (Tassew and Seifu 2011; Tiruneh 1996). This might be due to poor and unhygienic bedding condition in the majority of farms and absence of teat dipping and disinfection practices in the current study. These practices have been known as critical components of mastitis prevention and control program in dairy herds (Galton et al. 1986). Other findings by different researchers confirm that $E$. coli grow well in milk and hence endanger its keeping milk quality (Frazeir and Westhoff 1988). E. coli and coliforms are often used as indicator microorganisms, and the presence of $E$. coli in milk samples implies a risk that other enteropathogenic bacteria may be present in the sample (Najib 2003; Olatunji et al. 2009; Arafa and Soliman 2013).

Table 2 Antibiotic sensitivity pattern of bacterial isolates in milk samples collected from Jigjiga city

\begin{tabular}{|c|c|c|c|c|c|c|c|c|c|c|c|c|}
\hline \multirow[t]{2}{*}{ Antimicrobial } & \multicolumn{3}{|c|}{ E. coli $(\mathrm{n}=70)$} & \multicolumn{3}{|c|}{ Salmonella sp. $(\mathrm{n}=4)$} & \multicolumn{3}{|c|}{ Shigella sp. $(\mathrm{n}=21)$} & \multicolumn{3}{|c|}{ Proteus sp. $(\mathrm{n}=9)$} \\
\hline & R (\%) & I (\%) & $\mathrm{S}(\%)$ & $R(\%)$ & I (\%) & S (\%) & R (\%) & I (\%) & S (\%) & R (\%) & I (\%) & $S(\%)$ \\
\hline Amoxicillin & $15(21.4)$ & $31(44.3)$ & $24(34.3)$ & $2(50)$ & $1((25)$ & $1(25)$ & $2(9.5)$ & $11(52.4)$ & $8(38.1)$ & $1(11.1)$ & $6(66.7)$ & $2(22.2)$ \\
\hline Ampicillin & $21(30)$ & $28(40)$ & $21(30)$ & $1(25)$ & $1(25)$ & $2(50)$ & $8(38.1)$ & $8(38.1)$ & $5(23.8)$ & $5(55.6)$ & $3(33.3)$ & 1(11.1) \\
\hline Ciprofloxacin & $7(10)$ & $17(24.3)$ & $46(65.7)$ & $1(25)$ & $1(25)$ & $2(50)$ & $2(9.5)$ & $6(28.6)$ & 13(61.9) & $0(0.0)$ & $3(33.3)$ & $6(66.7)$ \\
\hline Co-trimoxazole & $12(17.1)$ & $22(31.4)$ & $36(51.4)$ & $1(25)$ & $2(50)$ & $1(25)$ & $0(0.0)$ & $4(19.0)$ & $17(81)$ & $1(11.1)$ & $3(33.3)$ & $5(55.6)$ \\
\hline Chloramphenicol & $15(21.4)$ & $26(37.1)$ & 29(41.4) & $1(25)$ & $2(50)$ & $1(25)$ & $3(14.3)$ & 7(33.3) & $11(52.4)$ & $1(11.1)$ & $5(55.6)$ & 3(33.3) \\
\hline Gentamycin & $21(30)$ & $35(50)$ & $14(20)$ & $1(25)$ & $2(50)$ & $1(25)$ & $4(19.0)$ & $10(47.6)$ & 7(33.3) & $2(22.2)$ & $4(44.4)$ & 3(33.3) \\
\hline Doxycycline & $30(42.9)$ & $27(38.6)$ & 13(18.5) & $1(25)$ & $2(50)$ & $1(25)$ & $6(28.6)$ & $10(47.6)$ & $5(23.8)$ & $2(22.2)$ & $3(33.3)$ & $4(44.4)$ \\
\hline
\end{tabular}

$R$ Resistance, I Intermediate, $S$ Sensitive, $n$ number 
Table 3 Antimicrobial susceptibility pattern of $S$. aureus isolates $(n=29)$ from milk samples collected from Jigjiga city

\begin{tabular}{llll}
\hline Antimicrobial & Susceptible number (\%) & Intermediate number (\%) & Resistant number (\%) \\
\hline Pencillin (P) & $1(3.4)$ & $1(3.4)$ & $27(93.1)$ \\
Chloroamphenicol (CH) & $11(37.9)$ & $10(34.5)$ & $8(27.6)$ \\
Cephalothin (KF) & $15(51.7)$ & $5(17.2)$ & $9(31.0)$ \\
Gentamycin (CN) & $10(34.5)$ & $12(41.4)$ & $7(24.1)$ \\
Erythromycin (E) & $5(17.2)$ & $17(58.6)$ & $7(24.1)$ \\
Clindamycin (DA) & $9(31.0)$ & $16(55.2)$ & $4(13.8)$ \\
Tetracycline (TE) & $5(17.2)$ & $4(13.8)$ & $20(69)$ \\
Amoxicillin + clavulanic & $19(65.5)$ & $0(0.0)$ & $10(34.5)$ \\
Rifampicin (RD) & $27(93.1)$ & $1(3.4)$ & $1(3.4)$ \\
Oxacillin (OX) & $18(62.1)$ & $2(6.9)$ & $9(31.0)$ \\
Vancomycin (VA) & $24(82.8)$ & $3(10.3)$ & $2(6.9)$ \\
Sulphamethoxazole-timethoprim (SXZ) & $19(65.5)$ & $3(10.3)$ & $7(24.1)$ \\
\hline
\end{tabular}

Our results indicated that $24.2 \%$ of the samples were positive for S.aureus. This is a favorable finding because, for human health some strains of $S$. aureus are capable of producing heat stable enterotoxins (Asperger 1994). A comparable finding to our result was reported by Abebe et al. (2013) that S.aureus prevalence was $15.5 \%$ in raw milk samples. In contrast to this, different literatures revealed a very significant isolation rate of $S$. aureus from raw milk samples (Olatunji et al. 2009; Pourhassan and Taravat-Najafabadi 2011; Mohanty et al. 2013; Sanaa et al. 2005). Although the prevalence of $S$. aureus has been reported to vary with the size and geographic region of the area sampled, a high proportion of these bacteria in milk relates to poor hygiene practices. Based on observations made during the collection of samples, we therefore report that improper hygiene and poor farm management practices contributed to the

Table 4 The predominant MAR phenotypes for S. aureus isolated from milk samples $(n=29)$ collected from Jigjiga city

\begin{tabular}{lllc}
\hline MDR patterns & Phenotype & $\begin{array}{l}\text { Number } \\
\text { observed }\end{array}$ & Percentage \\
\hline Three & PG-TE-AC & 2 & 6.9 \\
& PG-TE -Ox & 7 & 24.1 \\
Four & PG-TE-Ox- KF & 4 & 13.8 \\
& PG-TE- AC-Ox & 1 & 3.4 \\
Five & PG-TE-AC-E-Ox & 2 & 6.9 \\
Six & PG-TE-AC-E-SXZ-Ox & 5 & 17.2 \\
Eight & PG-TE-AC-E-SXZ-Ox- CN & 1 & 3.4 \\
& PG-TE-AC-E-SXZ-Ox- CN- CH & 1 & 3.4 \\
& PG-TE-AC-E-SXZ-Ox- CN- VA & 1 & 3.4 \\
\hline
\end{tabular}

The percentage representations of the phenotypes were obtained by dividing the number of a particular phenotype by the total number of multiple antibiotic resistant isolates identified in a given area. VA Vancomycin, $P G$ Penicillin G, SXZ Sulphamethoxazole-timethoprim, E Erythromycin, Ox Oxacillin, AC Amoxicillin-Clavulanic Acid, TETetracycline, KF Cephalothin; CN Gentamycin, $\mathrm{CH}$ Chloroamphenicol presence of $S$. aureus in the milk. In this study low salmonella $s p$. isolation rate with $3.3 \%$ was found. Junaidu et al (2011), Forough et al. (2012) and Sanaa et al.(2005) had reported comparable findings with $2.17 \%$, $4 \%$ and $1.43 \%$ prevalence respectively. Addis et al. (2011) reported a prevalence of $10.7 \%$ from raw milk which is higher than the present report. In the other study by Addis et al. (2011) from 195 dairy cows tested $28.6 \%$ were positive from milk samples. Akoachere et al.(2009) in Cameroon reported a high prevalence (27 \%) of Salmonella among cattle. This may be due to the difference in the living condition, like housing conditions, feeding habits, types of feed given for the cattle, of the two cattle populations. The detection of Salmonella in $3.3 \%$ of the samples tested indicates that the degree of prevalence of the pathogen in raw milk in jigjiga is relatively higher than originally believed. Although contamination of dairy products currently accounts for a small percentage of foodborne illness, it is clear that raw milk consumption and the consumption of products made with raw milk present some risk. Although proper pasteurization minimizes these risks to the public, there is a small but growing group of people that consume unpasteurized milk or milk products, either for practical or cultural reasons, or because of perceived health benefits (Karns et al. 2005). Although the levels of Salmonella in the milk samples tested here seemed to be very low and the infectious dose for this organism is low, the potential for this organism to grow in improperly stored raw milk and in products made from raw milk presents a public health risk, particularly to susceptible members of the population.

The isolation rates of proteus Sp. in this study (7.5\%) is comparable with the report by Junaidu et al (2011) with $8.69 \%$ prevalence. Most of the organisms identified in this study were enteric bacteria indicating probable faecal contamination of the milk as a result of poor 
hygiene. The practice of pooling milk from different sources by traders, and the absence of pasteurization generally observed among them could increase the risk posed by such organisms.

In the present study, Doxycycline had the highest resistance rates in E. coli. In contrast to this, fairly higher resistant rate was recorded in Ampicillin (100\%) and Amoxicillin (42.11\%) (Thaker et al. 2012). On the other hand the highest resistance rate for Salmonella $s p$. in this report was observed to Amoxicillin (50 \%). Different researchers reported antimicrobial resistant Salmonella isolates of milk in their previous studies from Ethiopia (Molla et al. 2003; Mekonnen et al. 2005) and from other countries (White et al. 2001). Forough et al. (2012) reported that salmonella $s p$. isolates were resistance to Ampicillin (42.58 \%), Tetracycline (42.58 \%) and Nalidixic acid (78.57 \%). Addis et al. (2011) reported a high resistance rate salmonella isolates to ampicillin (100\%). The remarkable degree of resistance to many drugs represents public health hazard due to the fact that food borne outbreaks would be difficult to treat and this pool of MDR Salmonella in food supply represents a reservoir for the transferable resistant genes (Diaze De Aguayo et al. 1992). The reasons for the recovery of antimicrobial resistance Salmonella isolates were most likely due to the indiscriminate use of antimicrobials (WHO 1988), self-medication and administration of sub therapeutic dose of antimicrobials to livestock for prophylactic purpose (Acha and Szyfers 2001). Antimicrobial use in animal production systems has long been suspected to be a cause of the emergence and dissemination of antimicrobial resistant Salmonella (Forough et al. 2012).

In this study the highest resistance rate for shigella sp. was observed to Ampicillin (38.1\%) followed by Doxycycline $(28.6 \%)$. In contrast to our finding Sanaa et al. (2005) reported that shigella isolated from raw milk were sensitive to Gentamycin (64.3\%) followed by Chloramphenicol (92.1\%), and the highest antimicrobial resistant pattern was observed in Ampicillin and Amoxicillin (92.9 \%, $92.9 \%$ ) followed by penicillin (42.9 \%). In agreement with our result Ayalu et al. (2011) reported that shigella isolates were $100 \%$ resistant to Ampicillin and Amoxicillin but sensitive to Chloramphenicol, Gentamicin, and Norfloxacin(41.2 \%, $88.2 \%$, and $94.1 \%)$ respectively. Shiferaw et al. (2012) reported that $74 \%$ shigella isolates were resistant to Ampicillin, and $58 \%$ to Streptomycin. On the other hand, All the Shigella isolates were resistant to Ampicillin, $94 \%$ to Tetracycline, and $82 \%$ to Ciprofloxacin in a report by Debdutta et al. (2012).

The observations made in the present study clearly proved that $S$. aureus showed resistance to all antimicrobials tested except for rifampicin and Vancomycin (Table 3). These indicate that the problem is highly distributed and disseminated. Moreover, the overall resistance of
S. aureus isolates to vancomycin, rifampicin, clindamycin and gentamycin showed less than $25 \%$ of resistance and this is similar with the report of Ma et al. (2006) from the dairy farm in Taiwan. The reason why these antimicrobials were less resistant might be they are not frequently used in the study area in veterinary services, and perhaps in human medicine. Similar suggestion was given by Jaims et al.(2002) that the development of antimicrobial resistance is nearly always as a result of repeated therapeutic and/or indiscriminate use of them. However, the present study has demonstrated the existence of alarming level of resistance of S. aureus to commonly used antimicrobials (pencillin $\mathrm{G}$ and tetracycline) in the study area. This is due to the fact that tetracycline and penicillin are frequently and improperly used antimicrobials in animal and human treatment. The results were in accordance with reports from earlier studies in other countries (Jakee et al. 2008; Edward et al. 2002; Gentilini et al. 2002) suggesting a possible development of resistance from prolonged and indiscriminate usage of some antimicrobials. This is in contrast with the report of Ma et al. (2006) on his report with respect to pencillin and tetracycline in Taiwan. This is not surprising because penicillin $G$ and tetracycline are the most commonly used antimicrobials for the treatment of infection or mastitis in veterinary practice in Ethiopia. Moreover, penicillin resistance is plasmatic and, it spread out very quickly to several other strains. Pereira et al. (2009) showed that 70 to $73 \%$ of $S$. aureus strains isolated from various foods were resistant to $\beta$-lactam such as pencillin and ampicillin. Staphylococci are frequently isolated from bovine mastitis which is one of the most common causes for the use of antimicrobial in lactating dairy cows. Similarly, the present investigation indicated that the resistance pattern of penicillin was found to be $93.1 \%$ (Table 3) which is similar to the finding made by Tariku et al.(2011) (87.2 \%) in Ethiopia, Landin (2006) (80 \%) in Sweden, Gooraninejad et al. (2007) (57 \%) in Iran and Myllys et al.(1998) (50 \%) in Finland. This is in contrast to findings observed by Adesiyun (1994) who reported $23 \%$ of resistance to pencillin G in West India.

Moreover, the present study showed the resistance of S. aureus to tetracycline (69\%), amoxicillin-clavulinic acid (34.5\%), oxacillin (31\%), cephalothin (31\%), chloramphenicol (27.6\%), sulphamethoxazole-trimethoprim (24.1\%), erythromycin (24.1\%), gentamycin (24.1\%), clindamycin (13.8\%) observed in milk samples taken from dairy cows in jigjiga city. This is in accordance with the findings of Tariku et al.(2011) who reported resistance of $S$. aureus to amoxicillin-clavulinic acid (46\%), chloroamphenicol (16\%), vancomycin (3\%), but it disagree with the observation made by Tariku et al. (2011) in the case of tetracycline $(0 \%)$, Co-trimoxazole $(0 \%)$ and clindamycin $(4 \%)$ in dairy farms in Jimma town. The probable explanation could be that $S$. aureus strains 
have the capacity to change their resistance behavior to the exposed antimicrobials.

With a particular emphasis to tetracycline, the present observation agrees with preliminary finding conducted by Bayhun (2008) (55.3 \%). However, apparent difference was observed in the report of Tariku et al.(2011) (0\%). This is due to the fact that tetracycline is the most commonly used antimicrobial in the treatment of infections in the livestock sector in Ethiopia. Moreover, tetracycline is widely used as growth factors in veterinary medicine for livestock rearing as well in the treatment of bacterial infection occurring in human medicine (Ardic et al. 2005). Furthermore, the resistance profile of $S$. aureus to amoxicillin-clavulinic acid and oxacillin in milk samples was found to be high. This is due to the fact that resistance of $S$. aureus to pencillin G, amoxicillin and oxacillin may be attributed to the production of $\beta$-lactamase, an enzyme that inactivates pencillin and closely related antimicrobial. It is believed that about $50 \%$ of mastitis causing $S$. aureus produces $\beta$-lactamase (Green and Bradely 2004). Likewise, $S$. aureus showed resistance to vancomycin and clindamycin. This might indicate transfer of resistant strain among environment, livestock and human since this antimicrobials are not used in veterinary practice.

The MAR phenotypes (Table 4) obtained in the study correlated with the percentage of antibiotic resistance. Although the development of resistance to a particular antibiotic depends on the level of exposure to the antimicrobials, (Rychlik et al. 2006) there are many other factors that are involved. We are therefore suggesting that molecular methods be used to characterize these isolates for the presence of antibiotic-resistance determinants, which may provide data to support our conclusions. S. aureus is normally resident in humans; therefore, the $S$. aureus present in the cow's milk may have resulted from transmission from humans, which raises questions regarding the hygiene practices followed.

\section{Conclusions}

This study revealed that raw cow's milk in the study area could be an important source of infection with a wide range of organisms, particularly enteropathogens. An important source of microbial contamination of the milk is faecal pollution probably from cow dung. There is the need for instituting effective control measures to protect public health. This includes mandatory milk pasteurization by traders and improved hygienic handling of the commodity during milking, ensuring milking is not done on cow dung. The occurrence of multidrug resistance $S$. aureus should be under consideration during selection of antimicrobials for treatment of mastitis especially if the possibility exists in the transfer of resistance in or between microbial species. Moreover, $S$. aureus is a common human commensal, and multidrug resistant S. aureus may present without clinical illness. However, when they cause infection they are extremely serious. Furthermore, dairy cows become infected with multidrug resistant $S$. aureus, therefore diagnosis of $S$. aureus does not have implication for treatment only but also it indicates zoonotic transmission since it becomes reservoir for human infection. In practice of indiscriminate use of drugs should be controlled. Further studies that could incorporate isolation of milk contaminating bacteria to the species level should be done to evaluate the imminent danger posed by microbes from milks.

\section{Acknowledgements \\ Jigjiga University is greatly acknowledged for funding and providing all rounded technical assistance for the smooth accomplishment of this research. The authors are also highly indebted to Ethiopian Somali Regional Health Bureau, Regional Public Health and Research Laboratory for laboratory facilities.}

\section{Authors' contributions}

MA carried out the conception of the research concept and designed the methodology, data analysis and interpretation and preparation of the manuscript for publication. TW carried out the laboratory work, sample collection and revision of the manuscript. AN critically revised the proposal, designed the methodology, and reviewed the manuscript. All authors read and approved the final manuscript.

\section{Competing interests}

The authors declare that there is no financial or non-financial competing interest from anybody or institute. We also want to assure that we did not receive any technical assistant in developing the research concept or preparation of the manuscript.

\section{Author details}

${ }^{1}$ Faculty of Health Science, Department of Nursing, Woldia University, P.O.Box 400, Woldia, Ethiopia. ${ }^{2}$ College of Natural Sciences, Department of Biology, Wolkite University, P.O.Box 07, Wolkite, Ethiopia. ${ }^{3}$ College of Veterinary Medicine, Department of Veterinary Microbiology and Public Health, Jigjiga University, P.O.Box 1020, Jigjiga, Ethiopia.

Received: 3 February 2016 Accepted: 13 May 2016

Published online: 26 May 2016

\section{References}

Abebe B, Zelalem Y, Ajebu N. Hygienic and microbial quality of raw whole cow's milk produced in Ezha district of the Gurage zone, Southern Ethiopia. Wudpecker J Agric Res. 2012;1(11):459-65.

Abebe M, Daniel A, Yimtubezinash W, Genene T. Identification and antimicrobial susceptibility of S. aureus isolated from milk samples of dairy cows and nasal swabs of farm workers in selected dairy farms around Addis Ababa, Ethiopia. Afr J Microbiol Res. 2013;7(27):3501-10.

Acha PN, Szyfers B. Zoonoses and Communicable Diseases Common to Man and Animals: Bacteriosis and Mycosis. $3^{\text {rd }}$ ed.Vol I. Washington DC: Pan American Health Organization; 2001. p. 233-46.

Addis Z, Kebed N, Worku Z, Gezahegn H, Yirsa A, Kassa T. Prevalence and antimicrobial resistance of Salmonella isolated from lactating cows and in contact humans in dairy farms of Addis Ababa. BMC Infect Dis. 2011;11:222-8.

Adesiyun A. Characteristics of S. aureus strains isolated from bovine mastitic milk: Bacteriophage and antimicrobial agent susceptibility and enterotoxigenecity. J Vet Med. 1994:42:129-39.

Adesiyun AA, Webb L, Rahman S. Microbiological quality of raw cow's milk at collection centers in Trinidad. J Food Prot. 1995;58:139-46.

Akoachere TK, Tanih FN, Ndip ML, Ndip RN. Phenotypic Characterization of Salmonella Typhimurium Isolates from Food-animals and Abattoir Drains in Buea, Cameroon. J Health Popul Nutr. 2009;27(5):612-8.

Aneja RP, Muthur BN, Chandan RC, Banerejee AK. Technology of Indian milk products. New Delhi: Dairy Indian Yearbook; 2002. p. 183-96. 
Arafa M, Soliman M. Bacteriological Quality and Safety of Raw Cow's Milk and Fresh Cream. Slov Vet Res. 2013;50(1):21-30.

Ardic N, Ozyurt M, Sareyyupoglu B. Investigation of erythromycin and tetracycline resistance genes in Methicillin-resistant Staphylococci. Int J Antimicrob Agents. 2005;26:213-8.

Asperger H. Stapylococcus aureus. In: The Significance of Pathogenic Microorganisms in Raw Milk, International Dairy Federation. Brussels: IDF; 1994. p. 24-42.

Ayalu AR, Berhanu S, Jemal Y, Gizachew A, Sisay F, Jean MV. Antibiotic susceptibility patterns of Salmonella and Shigella isolates in Harar, Eastern Ethiopia. J Infect Dis Immun. 2011;3(8):134-9.

Bayhun S. Beta-lactamase activities and antibiotic resistance comparison of Staphylococcus aureus isolated from clinic and food material (M.Sc Thesis). Gazi University, Institute of Science Technology;2008. p.126

Bouazza F, Hassikou R, Ohmani F, Hmmamouchi J, Ennadir J, Qasmaoui A, et al. Hygienic quality of raw milk at Sardi breed of sheep in Morocco. Afr J Microbiol Res. 2012;6(11):2768-72.

Claeys WL, Cardoen S, Daube G, Block JD, Dewettinck K, Katelijne Dierick K, et al. Herman Raw or heated cow milk consumption. Rev Risks benefits Food Control. 2013;31:251-62.

Clinical and Laboratory Standards Institute (CLSI). Performance Standards for Antimicrobial Disk and Dilution Susceptibility Tests for Bacteria Isolated From Animals. Clin Lab Stand Inst. 2008;28:M31-A3.

Cruikshank R, Duguid JP, Marmoin BP, Swain RH. Medical microbiology. 12th ed. New York: Longman Group Limited; 1975. p. 34

CSA (Central Statistical Authority). Central Statistical Authority, Federal Democratic Republic of Ethiopia, Central Statistical Investigatory, Statistical Report. Addis Ababa: Central Statistical Authority of Ethiopia; 2003

Daka D, Gebresilassie S, Yihdego D. Antibiotic-resistance Staphylococcus aureus isolated from cow's milk in the Hawassa area, South Ethiopia. Ann Clin Microbiol Antimicrob. 2012;11:26.

Debdutta B, Sugunan AP, Haimanti B, Thamizhmani R, Sayi DS, Thanasekaran K, et al. Antimicrobial resistance in Shigella -rapid increase \& widening of spectrum in Andaman Islands, India. Indian J Med Res. 2012;135(3):365-70.

Diaze De Aguayo ME, Duarte AB, Montes De Oca Canastillo F. Incidence of multiple antibiotic resistant organisms isolated from retail milk products in Hermosillo, Mexico. J Food Prot. 1992;55(5):370-3.

Edward M, Anna K, Michal K, Henryka L, Krystyna K. Antimic-robial susceptibility of staphylococci isolated from mastitic cows. Bull Vet Inst. 2002;46:289-94.

Fadaei A. Bacteriological Quality of Raw Cow Milk in Shahrekord, Iran. Veterinary World. 2014;7(4):240-3.

Forough T, Elahe T, Manochehr M, Ebrahim R, Rafie S. Occurrence and Antibiotic Resistance of Salmonella spp Isolated from Raw Cow's Milk from Shahahrekord, Iran. Int J Microbiol Res. 2012;3(3):242-5.

Frazeir WC, Westhoff DT. Food Microbiology $\left(4^{\text {th }} e d\right)$. Singapore: Mcgraw-Hill Book Company; 1988. p. 419-28.

Galton DM, Petersson LG, Merril WG. Effects of Pre- Milking Udder Preparation on Bacterial Counts of in Milk and on Teat. J Dairy Sci. 1986;69:260-6.

Garedew L, Berhanu A, Mengesha D, Tsegay G. Identification of gram-negative bacteria from critical control points of raw and pasteurized cow milk consumed at Gondar town and its suburbs, Ethiopia. BMC Public Health. 2012;12:950.

Gentilini E, Danamiel A, Betancor M, Rebuelto MR, Fermepin RM, Detorrest RA. Antimicrobial susceptibility of coagulase-negative Staphylococci isolated from bovine Mastitis in Argentina. J Dairy Sci. 2002;85:1913-7.

Godefay B, Molla B. Bacteriological quality of raw milk from four dairy farms and milk collection center in and around Addis Ababa, Berl. Münch Tierarztl Wschr. 2000;113:1-3.

Gooraninejad S, Ghorbanpoor M, Salati AP. Antibiotic Susceptibility of Staphylococci isolated from bovine sub-clinical mastitis. Pak J Biol Sci. 2007;10:2781-3.

Green M, Bradely A. Clinical Forum- S. aureus mastitis in cattle UK. VET. 2004;9:4.

Hendriksen RS. A global Salmonella surveillance and laboratory support project of the World Health Organization: Laboratory Protocols (Susceptibility testing of Salmonella using disk diffusion). 2002. p. 3.

Hendriksen RS. A global Salmonella surveillance and laboratory support project of the World Health Organization: Laboratory Protocols (Isolation of Salmonella). 2003. p. 4.

Jaims E, Montros LE, Renata DC. Epidemiology of drug resistance; the case of Staphylococcus aureus and Coagulase negative Staphylococci infections. Salud Publica Mex. 2002:44:108-12.

Jakee J, Ata S, Nagwa M, Bakry SA, Zouelfakar EE, Gad El-Said WA. Characteristics of $S$. aureus strains isolated from human and animal sources. Am-Euras J Agric Environ Sci. 2008:4:221-9.
Junaidu AU, Salihu MD, Tambuwal FM, Magaji AA, Jaafaru S. Prevalence of Mastitis in Lactating Cows in some selected Commercial Dairy Farms in Sokoto Metropolis. Adv Appl Sci Res. 2011;2(2):290-4.

Karns JS, Van Kassel JS, McKluskey BJ, Perdue M. Prevalence of Salmonella enteric in bulk tank milk from US dairies as determined by Polymerase Chain Reaction. J Dairy Sci. 2005;88:3475-9.

Landin $\mathrm{H}$. Treatment of mastitis in Swedish dairy production (in Swedish with English summary). Svensk Veterina"rtidning. 2006;58:19-25.

Ma Y, Chang SK, Chou CC. Characterization of bacterial susceptibility isolates in sixteen dairy farms in Taiwan. J Dairy Sci. 2006;1:55-6.

Mekonnen H, Workineh S, Bayleyegne M, Moges A, Tadele K. Antimicrobial susceptibility profile of mastitis isolates from cows in three major Ethiopian dairies. Med Vet. 2005;176(7):391-4.

Mennane Z, Ouhssine M, Khedid K, Elyachioui M. Hygienic Quality of Raw Cow's Milk Feeding from Domestic. Int J Agri Biol. 2007:9(1):1560-8530.

Mohanty NN, Das P, Pany SS, Sarangi LN, Ranabijuli S, Panda HK. Isolation and antibiogram of Staphylococcus, Streptococcus and E. coli isolates from clinical and subclinical cases of bovine mastitis. Vet World. 2013;6(10):739-43.

Molla B, Alemayehu D, Salah W. Source and distribution of Salmonella serovars isolated from food animals, slaughter house personnel and retail meat products in Ethiopia: 1997-2002. Ethiopia J Health Dev. 2003;17:63-70.

Myllys V, Asplund K, Brofeld E, Hirevela-Koski V, Honkanen-Buzalski T. Bovine Mastitis in Filand in 1988 and 1995. Changes in Prevalence and Antimicrobial resistance. Acta Vet Scand. 1998;39:119-26.

Najib G. Risk assessment of dairy products, Consumer committee seminar,Msca Tour Municipality MM Service, Columbia USA. 2003.

Olatunji EA, Ahmed I, ljah UJ. Evaluation of microbial qualities of skimmed milk (nono) in Nasarawa State, Nigeria. Proceeding of the $14^{\text {th }}$ Annual Conf. of Ani.Sc. Asso. of Nig. (ASAN) LAUTECH Ogbomoso, Sept. 14 ${ }^{\text {th }}-17^{\text {th }}, 2009.2009$

Pereira V, Lopes C, Castro A, Silva J, Gibbs P, Teixeira P. Characterization for Enterotoxins production, virulence factors and antibiotic susceptibility of $S$. aureus isolates from various food in Portugal. Food Microbiol. 2009;26:278-82.

Pourhassan M, Taravat-Najafabadi ART. The spatial distribution of bacterial pathogens in raw milk consumption on Malayer City, Iran. Shiraz E Med J. 2011;12:2-10.

Robinson RK. Dairy Microbiology Handbook: The Microbiology of Milk and Milk Products. 3rd ed. USA: John Wiley \& Sons, Inc; 2002. p. 51-305.

Rychlik I, Gregorova D, Hradecka H. Distribution and function of plasmids in Salmonella enterica. Vet Microbiol. 2006;112(1):1-10.

Sanaa OY, Nazik EA, Ibtisam EM, Zubeir EL. Incidence of Some Potential Pathogens in Raw Milk in Khartoum North (Sudan) and Their Susceptibility to Antimicrobial Agents. J Anim Vet Adv. 2005;4(3):356-9.

Shiferaw B, Solghan S, Palmer A, Joyce K, Barzilay EJ, Krueger A, Cieslak P. Antimicrobial susceptibility patterns of Shigella isolates in Foodborne Diseases Active Surveillance Network (FoodNet) sites, 2000-2010. Clin Infect Dis. 2012;54 Suppl 5:S458-63.

Solomon M, Mulisa M, Yibeltal M, Desalegn G, Simenew. Bacteriological quality of bovine raw milk at selected dairy farms in Debre Zeit town, Ethiopia. Compr J Food Sci Technol Res. 2013;1(1):1-8.

Soomro $\mathrm{AH}$, Arain MA, Khaskheli M, Bhuto B. Isolation of $E$. coli from raw milk and milk products in relation to public health sold under market conditions at Tandonjam, Pakistan. J Nutr. 1996;1(3):151-2.

Tariku S, Jemal H, Molalegne B. Prevalence and susceptibility assay of Staphylococcus aureus isolated from bovine mastitis in dairy farms in Jimma town South West Ethiopia. J Anim Vet Adv. 2011;10:745-9.

Tassew A, Seifu E. Microbial Quality of Raw Cow's Milk Collected from Farmers and Dairy Cooperatives in Bahir Dar Zuria and Mecha District, Ethiopia. Agric Biol J N Am. 2011;2(1):29-33.

Thaker HC, Brahmbhatt MN, Nayak JB. Study on occurrence and antibiogram pattern of E. coli from raw milk samples in Anand, Gujarat, India. Vet World. 2012:5(9):556-9.

Tiruneh Z. A Study on Bovine Subclinical Mastitis at Stella Dairy Farm, DVM Thesis. Addis Ababa: Faculty of Veterinary Medicine, Addis Ababa University; 1996. p. 30-45.

White DG, Zhao S, Sudler R, Ayers S, Friedman S, Chen S, et al. The isolation of antibiotic-resistant Salmonella from retail ground meats. New Engl J Med. 2001;345(16):1147-54.

World Health Organization. Salmonellosis Control: The Role of Animal and Product Hygiene, Technical Report Series, 774. Geneva: WHO; 1988. 